\title{
De materia medica: where art and scientific principles come together
}

\author{
Elif OZDOGAN
}

\begin{abstract}
This essay interprets and analyses the painting called "Dioscorides describing the mandrake", which is currently located in a permanent exhibition at Wellcome Collection in London, UK. The painting features Pedanius Dioscorides, a Greek botanist and pharmacologist who practiced in the Roman Empire during the rule of Nero. Dioscorides is known for his influential De Materia Medica, a five-volume book on medicinal uses of various plants and herbs. What makes this script special and influential is that it included a vast amount of herbs, detailed descriptions, scientific observations, as well as a scientific classification and order. Upon reflection on this piece of art, I am reminded of the medical realm that we are gradually becoming a part of as medical students. There is immense passion, knowledge and intelligence in how medicine became modern medicine today. For me, the painting on Dioscorides' De Materia Medica is a compelling visual representation of centuries - long endeavor.
\end{abstract}

Elif Ozdogan ( $\square$ )

School of Medicine, Koc University, Istanbul, Turkey

e-mail: elifozdogan15@ku.edu.tr

\section{Introduction}

I was mesmerised by the permanent exhibition, Medicine Man at Wellcome Collection in London. The exhibition comprises a vast array of medical curiosities from various cultures and times. Among all the valuable artefacts, Ernest Board's "Dioscorides describing the mandrake" created a special interest in me to pursue what is behind this major artpiece further (Figure 1) [1].

The oil painting shows Pedanius Dioscorides, a Greek botanist and pharmacologist eagerly writing on what seems like a bulky journal, while two figures at the back are engrossed in making a portrait of a herb. Dioscorides practised at the time of Nero and wrote his influential De Materia Medica between 5070 C.E. De Materia Medica, a five-volume book on medicinal uses of herbs, became the basis for pharmaceutical and herbal writing for 1600 years, and probably is what Dioscorides seems to be composing in this painting [2].

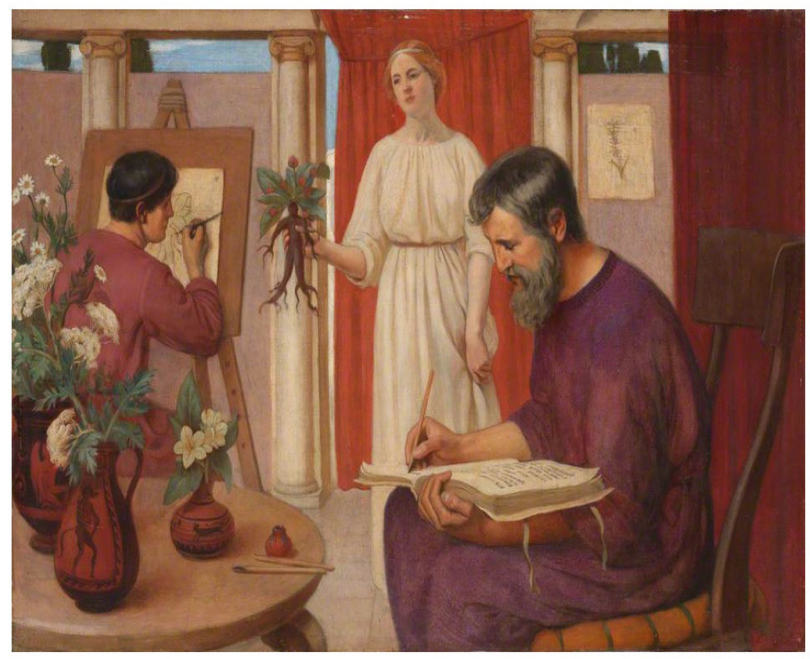

Figure 1. Dioscorides describing the mandrake. Oil painting by Ernest Board [1]. 
I wanted to reflect upon this artefact because I have encountered mandrake, the herb portrayed in the centre, as a recurrent symbol in a multitude of important literary works such as Shakespeare's Othello. I was not surprised to see that Board chose to depict Dioscorides working on mandrake out of 600 herbs mentioned in De Materia Medica but I could not explain why. This uncertainty led me to delve deeper into the folklore on mandrake.

Mandrake, arguably a "symbol of superstition", being shown as part of a medical writing in this painting, made me question whether this was to underscore that De Materia Medica was much more than just an organised compilation of medicinal herbs [3]. Could it also be seen as a revolution that laid the groundwork for evidence-based medicine, which divorces public belief from empirical data? Or could the plant be there to emphasise Dioscorides' determination to produce a complete work since mandrake was often evaded by many due to its use in witchcraft? I believe that both of these factors and many more contributed to making De Materia Medica timeless and universal, and in this essay I will explore these factors. Being yet a medical student, and hence a member of the public and the healthcare community at the same time, I was able to appreciate both the social and medical dimensions of this painting.

\section{View as a member of the public}

The first feature that caught my eye upon looking at the painting for the first time was the abundance of plants in the setting. The lower left corner shows various white flowers in vases, the mandrake is very centrally positioned and there is even an obscure drawing hung on the back wall that resembles the plant form. Board's depiction of Dioscorides describing the mandrake clearly associates Dioscorides with a fondness for plants, which might explain his ability to give meticulous descriptions of "the roots, foliage, and flowers" and his knowledge on "plant names, synonyms, and habitat information" although his training was primarily on medicine [4]. In my opinion, Board's technical choices convey Dioscorides' attachment to his work as well. His choice of predominantly light and rosy colours that create a peaceful setting, and the contently focused expression on Dioscorides' face work to suggest that Dioscorides is carrying out his job with delight. I believe that personal involvement is key to creating a thorough and successful product that is highly regarded by the public, whatever realm this may be in.
An author selects his/her audience partially by employing the appropriate language. Dioscorides, although he was a physician at the time, refrained from using a complicated language that would perhaps deter some people from referring to his work. His "writing style that employs a paucity of words" served to highlight content rather than style [5]. Consequently, De Materia Medica was not just a medical textbook of pharmacopoeia only read by doctors but a resource ubiquitously used by the public. It was even given as a wedding present to an emperor's daughter [6]. I think this intimates that Dioscorides had a clear vision on his mind and he strived to address the public in a straightforward manner, which is another factor that made De Materia Medica last a long time.

\section{View as a healthcare professional}

As someone who is yet training to be a healthcare professional, I can identify certain commonalities between the Western methodologies of mainstream medicine and the choices that Dioscorides made in De Materia Medica. I believe that many practices utilised by Dioscorides served to lay the foundations of modern, evidence-based medicine, which can explain why the text was not confined to an era.

The empirical character of the text that valued experimentation and evidence was one of such practices. Dioscorides employed a methodology to collect reliable information: for each plant he first read from the previous authorities, then travelled extensively to observe the habitats and to talk to people about their experiences and lastly tested them himself. He refrained from using anecdotes and did not trust word of mouth. Board expresses this as well in his portrayal of Dioscorides. We see Dioscorides in the same room with the plant in question, suggesting firsthand exposure and experience. As Paula De Vos suggests, "the timelessness of Dioscorides' work resulted from an empirical tradition based on trial and error" [7]. However, unlike the modern medicine today that looks for causation, Dioscorides remained an intelligent observer. This is perhaps a point at which the two approaches do not converge.

De Materia Medica was different to its predecessors as it had a systematic construct. This applies to both the way he organised the entries collectively and each entry on their own. It is interesting to note that Dioscorides was the first to organise entries by therapeutic action rather than by alphabetical order. In the preface, he complained that alphabetical order "splits off genera and properties 
from what most resembles them" [8]. This was a new and innovative idea, and even though De Materia Medica "was too subtle to be readily comprehended" [9] at the time of Dioscorides, I believe that this organisation made the work longer lasting by allowing the patient to find what they needed with ease in the later years. Moving on, each entry had a uniform construct that delineated the "description, preparation, and therapeutic properties" [8] of one substance in this order.

As a medical student who relies on functional groupings to remember, I understand how useful this profuse organisation would be for someone who wants to both retain and locate information.

\section{Conclusion}

I think that "Dioscorides describing mandrake" is a critical piece depicting a moment in the history of medicine that affected lives not only by outlining efficacious treatment but also by introducing an innovative way of thinking. Both as a member of the public and a healthcare professional, I appreciate what Dioscorides instigated during the 40 years of life he had.

Pedanius Dioscorides' De Materia Medica was truly timeless and universal: it remained in circulation for more than 1500 years and was translated to Latin, Arabic, Italian, Spanish, Greek, English, German and French. Although, it was supplanted by the textbooks of modern pharmacology, the most recent translation to English was completed in 2005, only fourteen years ago [5].

I believe that pondering and researching about the factors that made De Materia Medica influential for centuries made me realise the mentality and aspirations of a true scientist. It is now much more clear to me that in order to be successful one needs to have a clear purpose, self-discipline, an original way of thinking, fondness for the mission and a strong willingness to do work. Throughout my medical career I hope that I recall Dioscorides and what he taught me through this essay in order to be a focused clinician and a productive member of the society.

\section{Conflict of Interest: None}

Funding: None

\section{References}

1. Dioscorides describing the mandrake. Oil painting by Ernest Board. Credit: Wellcome Collection, Wellcome Library, London, UK. Available at: http://wellcomeimages.org/ indexplus/result.html (Accessed: 16 May, 2018)

2. National Institute of Health (2012) Greek medicine. Available at: http://www.nlm.nih.gov/hmd/greek/greek_dioscorides. html (Accessed: 14 April 2018)

3. Kobs M. The root of all evil? - The mandrake myth in German literature from 1673 to 1913. Masters thesis. University of Missouri. Available at: https://mospace. umsystem.edu/xmlui/bitstream/handle/10355/6554/research. pdf?sequence=3 2009 (Accessed: 11 April 2018)

4. Trueman, S. Ancient botanists. Available at: http://botany. about.com/od/HistoryBotany/a/Early-Botanists.htm 2015 (Accessed: 18 April 2018).

5. Riddle J. Book Review: De Materia Medica. Med Hist 2006;50: 553-4.

6. Cranch RL. The legacy of Dioscorides. Available at: http://www.motherearthliving.com/health-and-wellness/ dioscorides.aspx 1997 (Accessed: 11 April 2018)

7. De Vos P. European Materia Medica in historical texts: Longevity of a tradition and implications for future use. J Ethnopharmacol 2010;132:28-47. doi:10.1016/j. jep.2010.05.035.

8. Scarborough J, Nutton V. The Preface of Dioscorides' Materia Medica: introduction, translation, and commentary. Trans Stud Coll Physicians Phila 1982;4:187-227.

9. Osborn D. Dioscorides. Available at: http://www. greekmedicine.net/whos_who/Dioscorides.html 2015 (Accessed: 12 April 2018). 